\title{
$\mathrm{RF}$ sputtering으로 증착된 $\mathrm{ZnO}$ 박막을 전자 수송층으로 사용한 양자점 발광 다이오드에 관한 연구
}

강명석 · 김지완*

경기대학교 신소재공학과

\section{A Study on the ZnO Thin Film Deposited by RF Sputtering Method as an Electron Transport Layer in Quantum Dot Light-Emitting Diodes}

\author{
Myoungsuk Kang and Jiwan Kim* \\ Department of Advanced Materials Engineering, Kyonggi University, Suwon 16227, Republic of Korea
}

\begin{abstract}
We report a highly efficient quantum dot light emitting diode (QLEDs) with a radio frequency (RF) sputtered $\mathrm{ZnO}$ thin film as an electron transport layer (ETL) instead of the conventional $\mathrm{ZnO}$ nanoparticles (NPs) by solution process. ZnO NPs have been used as a key material to improve the performance of QLEDs, but the charge imbalance in $\mathrm{ZnO}$ NPs resulting from fast electron injection, and their limited uniformity are significant disadvantages. In this study, $\mathrm{ZnO}$ layers were deposited by $\mathrm{RF}$ sputtering with various $\mathrm{O}_{2}$ partial pressures. All of the $\mathrm{ZnO}$ films showed preferential growth along the (002) direction, smooth morphology, and good optical transmittance. To test their feasibility for QLEDs, we fabricated devices with RF sputtered $\mathrm{ZnO}$ layers as an ETL, which has the inverted structure of ITO/RF sputtered $\mathrm{ZnO} / \mathrm{QDs} / \mathrm{CBP} / \mathrm{MoO}_{3} / \mathrm{Al}$. The optical/ electrical characteristics of two devices, comprised of $\mathrm{RF}$ sputtered $\mathrm{ZnO}$ and $\mathrm{ZnO} \mathrm{NPs}$, were compared with each other. QLEDs with the sputtered ZnO ETL achieved a current efficiency of $11.32 \mathrm{~cd} / \mathrm{A}$, which was higher than the $8.23 \mathrm{~cd} / \mathrm{A}$ of the QLEDs with ZnO NPs ETL. Next, to find the optimum $\mathrm{ZnO}$ thin film for highly efficient QLEDs, deposition conditions with various $\mathrm{O}_{2}$ partial pressures were tested, and device performance was investigated. The maximum current efficiency was $13.33 \mathrm{~cd} / \mathrm{A}$ when the ratio of $\mathrm{Ar} / \mathrm{O}_{2}$ was 4:3. Additional oxygen gas reduced the $\mathrm{O}$ vacancies in the $\mathrm{ZnO}$ thin film, which resulted in a decrease in electrical conductivity, thereby improving charge balance in the emission layer of the QLEDs. As a result, we provide a way to control the $\mathrm{ZnO}$ ETL properties and to improve device performance by controlling $\mathrm{O}_{2}$ partial pressure.
\end{abstract}

(Received June 14 2021; Accepted July 9, 2021)

Keywords: Quantum dot, $\mathrm{ZnO}, \mathrm{RF}$ sputtering, Electroluminescence

\section{1. 서 론}

콜로이달 양자점(colloidal quantum dots, QDs)은 반도 체 나노 입자로 입자의 크기 조절을 통해 방출 파장의 조 절이 가능하며 좁은 반치폭으로 인한 뛰어난 색순도, 그리 고 유기물 계열의 발광 물질과 비교하였을 때 뒤쳐지지 않 는 양자 효율로 인해 새로운 디스플레이 후보 물질로 떠오 르고 있다 [1-3]. 특히 양자점 발광다이오드(quantum dot

- 김지완: 교수, 강명석: 석사과정

${ }^{*}$ Corresponding Author: Jiwan Kim

[Tel: +82-31-249-1308, E-mail: jiwank@kgu.ac.kr]

Copyright (c) The Korean Institute of Metals and Materials light-emitting diodes, QLEDs)는기존의 유기 발광 다이오 드(organic light-emitting diodes)와 유사한 구조를 가지고 있으면서도 유기물을 증착하기 위한 고진공 열 증착법을 사용하지 않고 용액 공정 방식의 스핀 코팅을 사용한다는 장점이 있다.

1994년에 최초의 QLEDs가 연구된 이후로, QLEDs의 성능을 개선하기 위해 QDs의 코어/쉘 구조를 최적화하는 다양한 연구가 진행되었으며, 소자 내에서 전하의 균형을 맞추기 위한 다양한 소자 구조가 연구되어왔다 [4-7]. 특히 전 자수송층(electron transport layer, ETL)과 발광층(emission layer, EML) 또는 정공수송층(hole transport layer, HTL)과 $\mathrm{EML}$ 사이에 polyethlyenimine, $\mathrm{Al}_{2} \mathrm{O}_{3}$ 등의 중간층을 삽입 
하는 등의 다양한 소자구조가 연구되고 있다 [8-10]. 현재 최대 외부 양자 효율(external quantum efficiency)이 $20 \%$ 가 넘는 $\mathrm{Cd}$ 계열 $\mathrm{QDs}$ 기반의 $\mathrm{QLEDs}$ 를 보고되었으며 [6], 최근에는 $\mathrm{Cd}$ 계열의 $\mathrm{QDs}$ 의 독성에 대한 환경 규제 때문에 $\mathrm{InP}, \mathrm{ZnTeSe}$ 기반의 비 $\mathrm{Cd}$ 계열의 $\mathrm{QDs}$ 을 사용한 뛰어난 성능을 가진 고효율 Cd-free QLED 또한 보고되고 있다 [11-13].

현재 효율적인 $\mathrm{QLED}$ 는 $\mathrm{ETL}$ 에 $\mathrm{ZnO}$ 기반 나노입자 (nanoparticles, NPs)가 사용되고 있다. $\mathrm{ZnO} \mathrm{NPs}$ 은 적절한 에너지 밴드갭, 견고성 및 용액 가공성, 조절 가능한 전기 전도도로 인해 $\mathrm{QLED}$ 의 핵심 재료로 사용되고 있다. $\mathrm{ZnO}$ $\mathrm{NPs}$ 은 QLEDs의 비약적인 발전을 이끌었지만 $\mathrm{ZnO} \mathrm{NPs}$ 에 존재하는 산소 공공의 존재와 빠른 전자 이동도로 인해 $\mathrm{EML}$ 에서의 전하 불균형은 아직도 해결해야할 문제로 남 아있다 [14-15].

$\mathrm{RF}$ sputtering 방식은 타겟 물질과 동일한 고품질 박막 의 뛰어난 재생산성과 박막의 특성이 공정의 변수를 조절 함에 따라 향상되며 증착 속도가 안정적인 장점이 있는 증 착 방법으로 알려져 있다 [16]. RF sputtering 방식 역시 과거 QLEDs 연구에 응용되었지만 제작된 소자의 성능이 낮아 연구진들의 이목을 집중시키지 못하였다 [17].

본 논문에서는 RF sputtering 방식으로 산소 분압을 조 절하여 증착된 $\mathrm{ZnO}$ 박막의 결정학적, 광학적, 전기적 특 성을 분석하였다. $\mathrm{ZnO}$ 박막은 다결정을 갖는 $\mathrm{ZnO} \mathrm{NPs}$ 와 달리 단일 피크 wurzite 구조의 단결정을 가지는 것이 $\mathrm{XRD}$ 분석으로 확인되었으며, $80 \%$ 이상의 높은 투과도를 나타냈다. ITO 기판 위에 RF sputtering 방식에 의해 형 성된 다양한 조건의 $\mathrm{ZnO}$ 박막을 $\mathrm{ETL}$ 로 사용하여 역구조 의 QLEDs를 제작해 전기적, 광학적 특성을 비교, 분석하 였으며, $\mathrm{ZnO} \mathrm{NPs}$ 를 사용하여 제작된 QLEDs와도 특성을 비교하였다. 먼저, $\mathrm{RF}$ sputtering 방식으로 제작된 $\mathrm{ZnO}$ 박막을 기반으로 한 QLEDs는 ZnO NPs를 사용한 경우보 다 휘도와 전류 효율에서 더 향상된 성능을 보였다. 또한 아르곤과 산소 가스의 비율을 조절하며 증착한 $\mathrm{ZnO}$ 박막 기반의 QLEDs는 산소 분압이 증가할수록 성능이 향상되 는 경향을 보였다. 이는 RF sputtering 방식으로 제작된 $\mathrm{ZnO}$ 박막 내의 산소 공공이 산소 분압의 증가로 인해 감 소해 전자의 이동이 억제되어 발광층에서 전자와 정공의 균형이 잘 맞기 때문으로 생각된다.

\section{2. 실험 방법}

본 연구에서는 먼저 bare glass 기판을 사용하여 증착된
$\mathrm{ZnO}$ 박막의 두께를 시간별로 측정하였으며 이를 토대로 $\mathrm{ZnO}$ target의 RF sputtering 속도를 계산하였다. $\mathrm{RF}$ sputtering 조건은 기저 압력은 $1.5 \times 10^{-5}$ Torr, 공정 압력은 $10 \mathrm{mTorr}$, target 인가 전력을 $100 \mathrm{~W}$ 로, 아르곤과 산소의 총 유량은 $35 \mathrm{sccm}$ 으로 고정하였으며 산소의 유량을 변화시키며 증착하였고 별도의 기판 열처리는 하지 않았다. 역구조의 QLEDs 제작을 위해 계산된 증착 속도를 토대로 $\mathrm{ZnO}$ 박막 을 $50 \mathrm{~nm}$ 의 두께로 ITO위에 증착 하였다. 그 후 ITO glass 를 IPA 및 증류수로 세척한 후 UV-Ozone 처리를 통해 기판 의 표면을 처리한다. 그 다음 ITO glass 위에 스핀 코팅 방 법으로 $\mathrm{EML}$ 로 사용될 $\mathrm{CdZnSeS@ZnS} \mathrm{구조의} \mathrm{녹색} \mathrm{QDs를}$ 톨루엔에 분산시켜 농도 $15 \mathrm{mg} / \mathrm{ml}$ 로 설정하여 $2000 \mathrm{rpm}$ 으로 20 초 동안 코팅하였다. QDs를 코팅하는 과정에서 별도의 열 처리 공정은 진행하지 않았으며, 열 증착법을 이용하여 HTL 로 사용된 $\mathrm{CBP}$, 정공 주입층(hole injection layer, $\mathrm{HIL}$ )으로 사용된 $\mathrm{MoO}_{3}$ 및 상부 전극으로 $\mathrm{Al}$ 을 각각 $40 \mathrm{~nm}, 10 \mathrm{~nm}$, $100 \mathrm{~nm}$ 의 박막을 형성하였다. 또한 RF sputtering 방식으로 증착된 $\mathrm{ZnO}$ 박막과 비교하기 위하여 $\mathrm{ZnO} \mathrm{NPs}$ 의 경우 $4000 \mathrm{rpm}, 60$ 초 코팅하였으며 그 외의 공정은 동일하게 제작 하였다. RF sputtering으로 증착된 $\mathrm{ZnO}$ 박막의 결정상의 분 석, 표면 특성 및 광학적 특성은 X-ray diffractometer (XRD, MiniFlex2, Rigaku), atomic force microscopy (AFM, PSIA XE-100), UV-Visible spectrometer (Optizen $\mathrm{POP}, \mathrm{KLab})$ 을 이용하여 진행되었다. 제작된 $\mathrm{QLEDs}$ 의 전기 적-광학적 특성은 CS-2000 spectroradiometer (Konica Minolta)와 2400 소스 미터(Keithley)을 사용해 분석하였다.

\section{3. 결과 및 고찰}

\section{1 제작된 $\mathrm{ZnO}$ 박막의 특성 확인}

$\mathrm{RF}$ sputtering 방식으로 다양한 아르곤과 산소의 비율 에 따라 증착한 $\mathrm{ZnO}$ 박막의 $\mathrm{XRD}$ 패턴을 그림 1(a)에 나타냈다. 일반적으로 $\mathrm{ZnO} \mathrm{NPs}$ 의 경우 다수의 피크가 나타나는 결정상을 갖는 것으로 알려져 있지만 [18], RF sputtering 방법으로 증착한 $\mathrm{ZnO}$ 박막은 산소 비율에 상 관없이 (002) 단일 피크를 갖는 wurzite 상이 형성된 것 을 확인하였다 [19]. 또한 $\mathrm{AFM}$ 을 이용한 표면 분석 결 과를 보면 그림 1(b)에 나타난 것처럼, $\mathrm{ZnO}$ 박막은 산 소의 비율에 의해 표면의 거칠기가 크게 변화하지 않으 며 매우 평탄함을 확인하였다.

\subsection{QLEDs 제작}

그림 2(a)에 $\mathrm{RF}$ sputtering 방법으로 증착된 $\mathrm{ZnO}$ 박막 

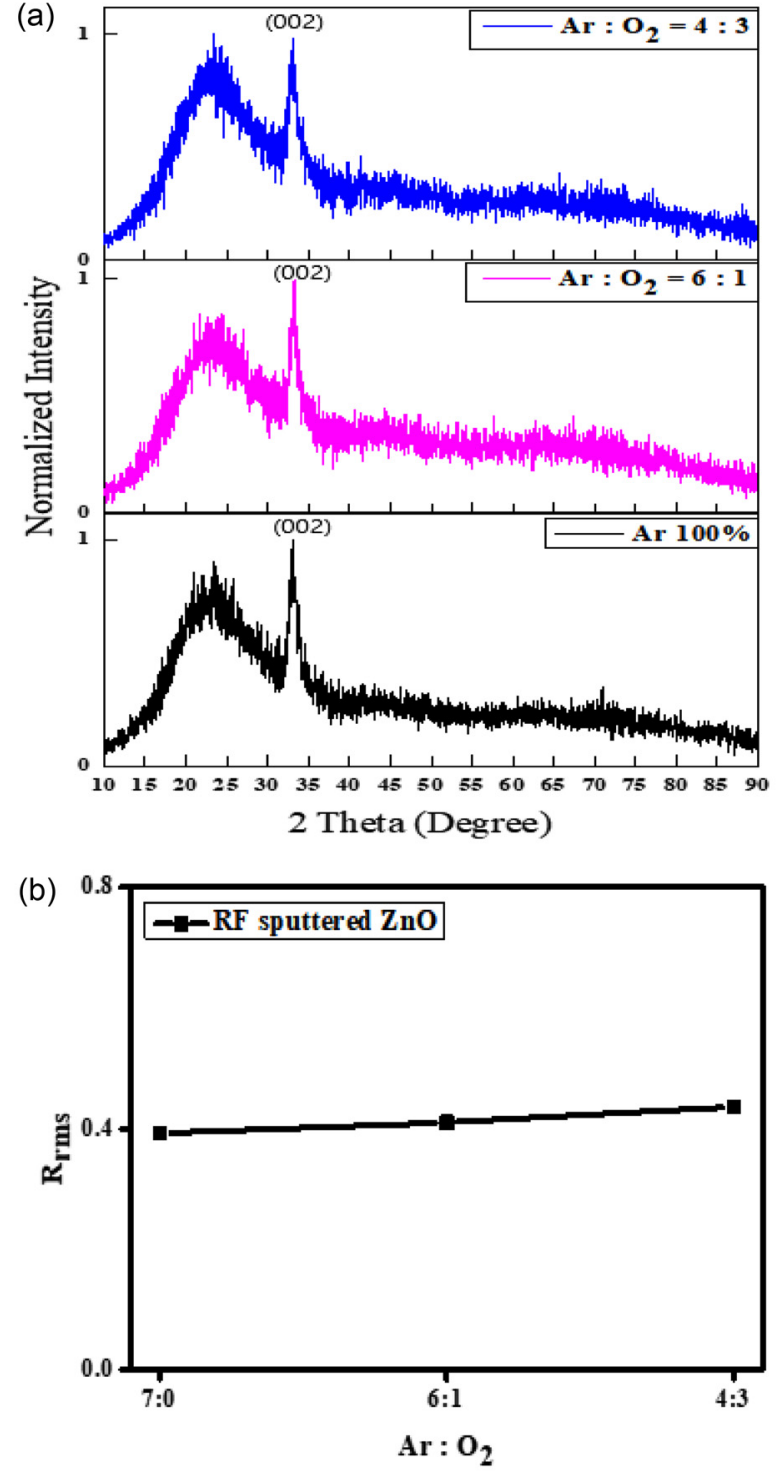

Fig. 1. (a) XRD patterns and (b) roughness of various sputtered $\mathrm{ZnO}$ thin films.

을 ETL로 사용한 QLEDs의 모식도를 나타냈다. QLEDs는 역구조로 제작되었으며, 하부 전극 $\mathrm{ITO}$ 를 음극, 상부 전극 $\mathrm{Al}$ 을 양극으로 사용하는 구조이다. $\mathrm{ITO}$ 를 통해 주입된 전 자는 $\mathrm{ETL}$ 역할을 하는 $\mathrm{ZnO}$ 층을 지나 발광 영역인 $\mathrm{QDs}$ 층으로 이동하며, $\mathrm{Al}$ 을 통해 주입된 정공은 각각 $\mathrm{HIL}$, $\mathrm{HTL}$ 역할을 하는 $\mathrm{MoO}_{3}, \mathrm{CBP}$ 층을 통과하며 발광층으로 이동한다. RF sputtering 방법으로 아르곤과 산소의 비율에 따라 증착한 $\mathrm{ZnO}$ 박막의 투과도를 그림 2(b)에 나타냈다. 투과도 측정 결과 $\mathrm{ZnO}$ 박막은 가시광선 영역에서 $80 \%$ 이 상의 높은 투과도를 나타냈다 [20]. ETL로 쓰인 $\mathrm{ZnO}$ 박 막의 투과도가 중요한 이유는 제작된 역구조 QLEDs는 배
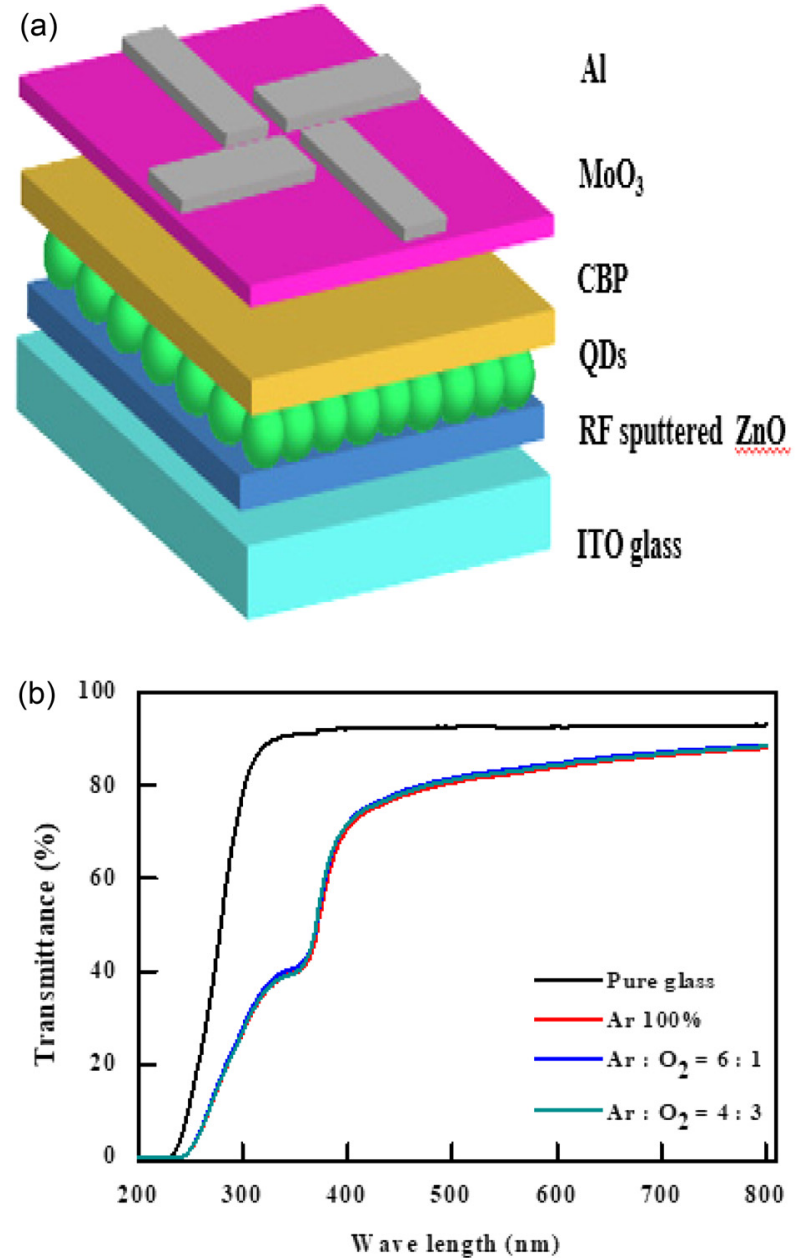

Fig. 2. (a) A schematic diagram of QLEDs with a sputtered $\mathrm{ZnO}$ thin film and (b) transmittance of sputtered $\mathrm{ZnO}$ thin films.

면 발광 방식으로 EML에서 발생한 빛이 하부의 ETL과 ITO 전극을 지나게 되기 때문이다. 따라서 높은 투과도의 $\mathrm{ETL}$ 물질 사용이 QLEDs 제작에 필수적이다.

\subsection{ETL로 RF sputtered $\mathrm{ZnO}$ 와 $\mathrm{ZnO} \mathrm{NPs}$ 을 사} 용한 QLEDs 성능 비교

용액공정으로 제작된 $\mathrm{ZnO} \mathrm{NPs}$ 은 QLED 소자 응용 연구에 서 현재 ETL로 가장 많이 사용되고 있다. RF sputtering 방 법으로 증착된 $\mathrm{ZnO}$ 박막과 $\mathrm{ZnO} \mathrm{NPs}$ 을 $\mathrm{ETL}$ 로 사용하였을 때의 차이를 확인하기 위해 QLEDs를 제작해 비교하였다.

그림 3(a)에서 RF sputtered $\mathrm{ZnO}$ 박막을 사용한 QLEDs에서 전류 밀도는 감소하는 경향을 보이며, 그림 3(b) 에서 최대 휘도가 $45,306 \mathrm{~cd} / \mathrm{m}^{2}$ 로 $\mathrm{ZnO} \mathrm{NPs}$ 의 $32,233 \mathrm{~cd} / \mathrm{m}^{2}$ 보다 증가하였다. 그림 3(c)에서는 RF sputtering 방법으로 증착된 $\mathrm{ZnO}$ 박막을 사용한 $\mathrm{QLEDs}$ 의 전류 효율이 11.32 

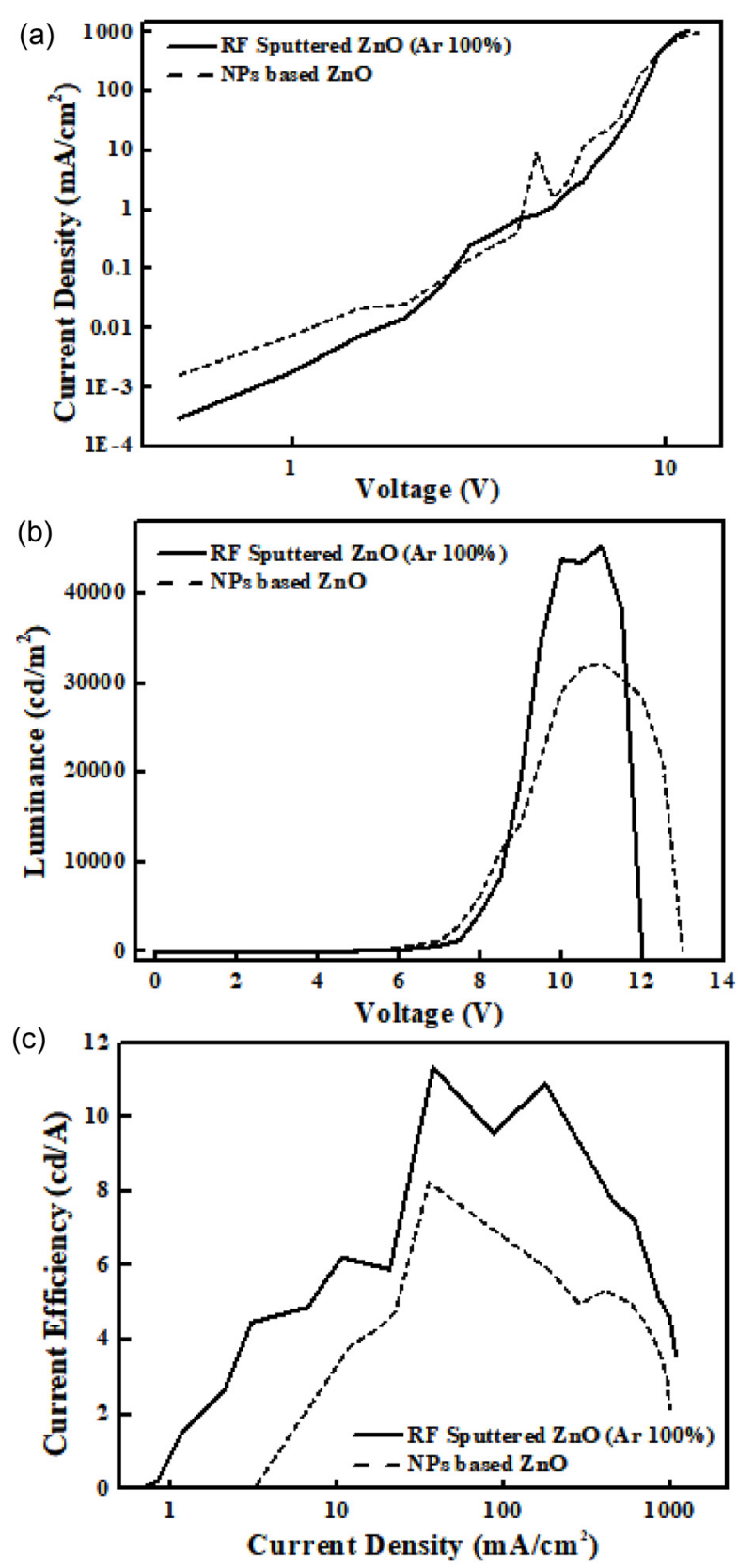

Fig. 3. Characteristics of (a) current density -voltage, (b) luminance - voltage and (C) current efficiency - voltage of QLEDs.

$\mathrm{cd} / \mathrm{A}$ 로 $\mathrm{ZnO} \mathrm{NPs}$ 의 $8.23 \mathrm{~cd} / \mathrm{A}$ 보다 더 높게 측정되었다. 따라서, $\mathrm{ZnO}$ 박막이 $\mathrm{ZnO} \mathrm{NPs}$ 보다 전자의 이동을 억제해 전자와 정공의 전하 균형을 향상시켜 더 높은 전류 효율을 나타낸 것으로 생각된다.

\section{4 다양한 $\mathrm{Ar}: \mathrm{O}_{2}$ 비율의 $\mathrm{ZnO}$ 박막을 사용한 QLEDs} 성능 비교

$\mathrm{RF}$ sputtering 과정에서 총 유량은 고정시키고 아르곤과
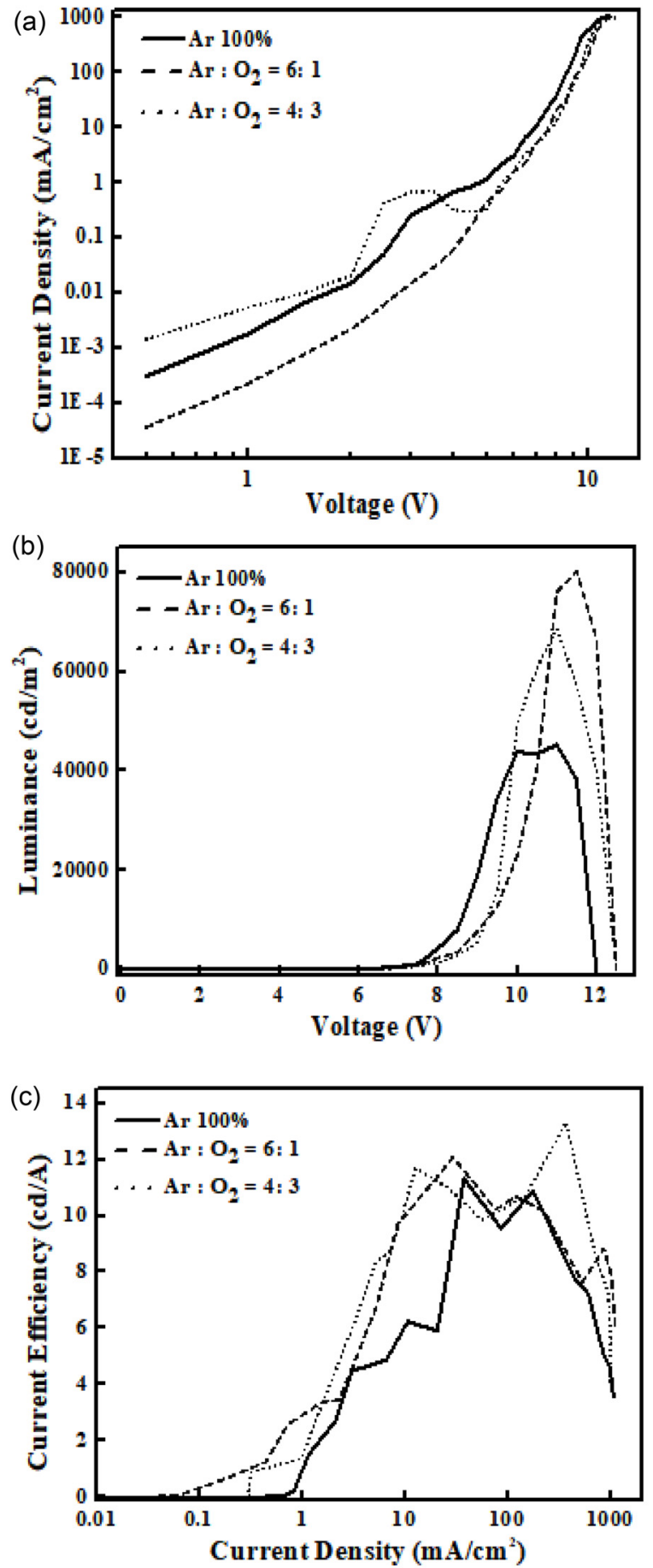

Fig. 4. Characteristics of (a) current density -voltage, (b) luminance - voltage and (C) current efficiency - voltage of QLEDs with various sputtered $\mathrm{ZnO}$ thin films.

산소의 비율을 변화시켜 $\mathrm{ZnO}$ 박막을 형성해 이를 $\mathrm{ETL}$ 로 사용해 QLEDs를 제작해 그 결과를 그림 4에서 확인하였 다. RF sputtering 과정에서 산소의 분압이 증가하는 $\mathrm{ZnO}$ 


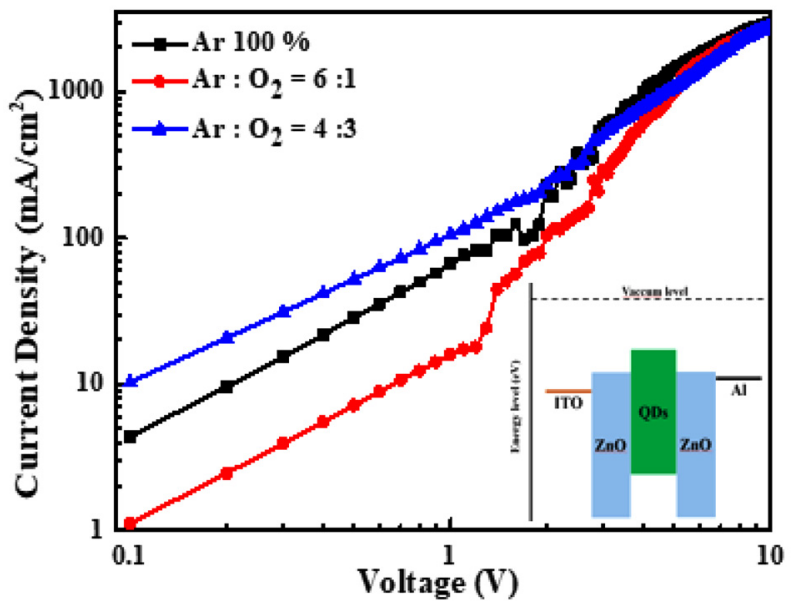

Fig. 5. Current density - voltage characteristic of electron - only devices with the structure of ITO/ sputtered $\mathrm{ZnO}$ thin films/QDs/ $\mathrm{ZnO} \mathrm{NPs} / \mathrm{Al}$.

박막이 산소의 분압을 가하지 않은 $\mathrm{ZnO}$ 박막과 비교하여 Turn-on 전압인 $4 \mathrm{~V}$ 이후로 전류 밀도가 낮은 결과를 보여 주었다. Yudai Kamada 등은 RF sputtering 과정 중에 아르곤 가스만을 주입하게 되면 산소의 공공과 $\mathrm{Zn}$ 침입형 원자가 defect를 가지는 $\mathrm{ZnO}$ 박막이 생성되지만, 산소 가 스를 아르곤 가스에 같이 주입하게 되면 생성되는 $\mathrm{ZnO}$ 박막 내부의 산소 공공의 형성을 억제할 수 있다고 보고하 였다 [21]. 결과적으로 제한된 전자의 이동이 전자와 정공 의 전하 불균형을 해소시켜 휘도와 전류효율의 상승을 일 으킨다. 그러나 Turn-on 전압 이후의 전압 영역에서는 산 소 분압의 차이가 전류 밀도에 크게 영향을 미치지 않았다. 아르곤과 산소의 비율이 6:1인 $\mathrm{ZnO}$ 박막을 사용한 QLEDs 의 최대 휘도와 전류 효율이 각각 $76,148 \mathrm{~cd} / \mathrm{m}^{2}, 12.10 \mathrm{~cd} /$ $\mathrm{A}$ 이며, 아르곤과 산소의 비율이 $4: 3$ 인 $\mathrm{ZnO}$ 박막을 사용한 QLEDs의 최대 휘도와 전류 효율은 각각 $68,710 \mathrm{~cd} / \mathrm{m}^{2}$, $13.33 \mathrm{~cd} / \mathrm{A}$ 이다.

그림 5 는 다른 산소가스 분압 조건에서 $\mathrm{RF}$ sputtering 방법으로 증착한 $\mathrm{ZnO}$ 박막을 사용해 electron-only devices (EOD)를 제작하고, 전기적 특성의 차이를 비교하 였다. $\mathrm{EOD}$ 를 제작하는 과정에서 RF Sputtering 방법으로 $\mathrm{QDs}$ 층과 $\mathrm{Al}$ 전극 사이에 $\mathrm{ZnO}$ 박막을 증착하면 $\mathrm{QDs}$ 층이 플라즈마에 의해 손상을 입기 때문에 $\mathrm{ZnO} \mathrm{NPs}$ 를 코팅하 여 $\mathrm{ITO} / \mathrm{ZnO} / \mathrm{QDs} / \mathrm{ZnO} \mathrm{NPs} / \mathrm{Al}$ 의 구조로 제작하였다. 아르 곤과 산소의 비율이 6:1인 $\mathrm{ZnO}$ 박막의 $\mathrm{EOD}$ 의 전류 밀도 가 가장 낮게 측정되었다. 이러한 전류 밀도의 경향성은 소자 결과에서 예상한 대로 $\mathrm{RF}$ sputtering 과정에서 형성
된 $\mathrm{ZnO}$ 박막의 산소의 공공이 주입된 산소 가스로 인해 감소되어 전자의 이동이 억제되기 때문으로 보인다. 그러 나 산소 가스의 주입의 증가와 전류 밀도의 감소는 완전히 비례하지 않으며 최적화되는 지점이 존재한다. 아르곤과 산 소의 비율이 4:3인 $\mathrm{ZnO}$ 박막의 경우 $6: 1$ 인 $\mathrm{ZnO}$ 박막의 전류 밀도보다 낮은 전압 영역에서는 높은 값을 보이나 Turn-on 전압 이후에는 다소 낮은 값을 나타낸다. 아르곤 과 산소의 비율이 4:3인 $\mathrm{ZnO}$ 박막을 QLEDs 소자에 사 용한 경우가 구동 영역에서 발광층에서 전하의 균형이 잘 맞아 전자와 정공의 재결합이 증가하게 되어 더 높은 전류 효율을 나타내는 것으로 사료된다. 이러한 결과를 통해 아 르곤과 산소의 비율이 $4: 3$ 인 조건이 최적화되는 지점이라 고 볼 수 있다.

\section{4. 결 론}

본 연구에서는 RF sputtering 방식으로 $\mathrm{ZnO}$ 박막을 형 성하고 형성된 $\mathrm{ZnO}$ 박막의 결정학적, 표면, 광학적 특성 을 분석하였다. 이를 토대로 QLEDs를 제작하여 기존의 $\mathrm{ZnO} \mathrm{NPs}$ 방식과 비교하였다. 또한 아르곤과 산소 가스의 비율의 변화가 소자의 성능에 미치는 영향을 분석하였다. 결과적으로 $\mathrm{RF}$ sputtering 방식으로 형성된 $\mathrm{ZnO}$ 박막의 QLEDs는 $\mathrm{ZnO} \mathrm{NPs}$ 대비 약 1.5 배의 휘도의 증가를 보여 주며, 전류 밀도가 낮아 전류 효율이 상승하였다. 또한 아 르곤과 산소의 비율을 변화시켜 형성한 $\mathrm{ZnO}$ 박막의 QLEDs는 산소의 분압이 증가하는 경우 Turn-on 전압 이 후로 전류 밀도가 감소하는 경향을 보였으며 이는 $\mathrm{RF}$ sputtering시 주입된 산소 가스로 인해 $\mathrm{ZnO}$ 박막의 산소 공공의 형성이 감소하여 전자의 이동이 제한되어 전자와 정공의 $\mathrm{EML}$ 에서의 재결합이 향상된 효과로 보인다. 또한 $\mathrm{EOD}$ 를 통해 주입되는 아르곤과 산소의 비율에 따른 $\mathrm{ZnO}$ 박막의 전기적 특성을 확인하였다. 본 연구를 통해 고효율 QLED소자 제작 시 RF sputtering으로 형성된 $\mathrm{ZnO}$ 박막 의 ETL로써의 가능성을 확인하였다.

\section{감사의 글}

본 연구는 2021 학년도 경기대학교 대학원 연구원장학 생 장학금 지원에 의하여 수행되었음. 또한 산업통상자원 부와 산업기술진흥원의 국제공동기술개발사업(P0011268)과 과학기술정보통신부의 재원으로 한국연구재단의 지원을 받 아 수행된 연구임(No. 2021R1F1A1061248). 


\section{REFERENCES}

1. L. Qian, Y. Zheng, J. Xue and P. H. Holloway, Nat. Photonics, 5, 534 (2011).

2. S. Coe, W.-K. Woo, M. Bawendi and V. Bulovic, Nature, 420, 800 (2002).

3. H. Zhang, S. Chen and X. W. Sun, ACS Nano, 12, 697 (2018).

4. V. Colvin, M. Schlamp and A. P. Alivisatos, Nature, 370, 354 (1994).

5. Y. X. Yang, Y. Zheng, W. Cao, A. Titiv, J. Hyvonen, J. R. Manders, J. Xue, P. H. Holloway and L. Qian, Nat. Photonics, 9, 259 (2015).

6. H. Shen, Q. Gao, Y. Zhang, Y. Lin, Q. Lin, Z. Li, L. Chen, Z. Zeng, X. Li, S. Wang, Z. Du, L. S. Li and Z. Zhang, Nat. Photonics, 13, 192 (2019).

7. H. Zhang, Q. Su and S. Chen, Nat. Commun., 11, 2826 (2020).

8. H. Jin, H. Moon, W. Lee, H. Hwangbo, S. H. Yong, H. K. Chung and H. Chae, RSC Adv., 9, 11634 (2019).

9. D. Kim, Y. Fu, S. Kim, W. Lee, K.-H. Lee, H. K. Chung, H.J. Lee, H. Yang, and H. Chae, ACS Nano, 11, 1982 (2017).

10. Y. Sun, Y. Jiang, H. Peng, J. Wei, S. Zhang and S. Chen, Nanoscale, 9, 8962 (2017).

11. Y.-H. Won, O. Cho, T. Kim, D.-Y. Chung, T. Kim, H.
Chung, H. Jang, J. Lee, D. Kim and E. Jang, Nature, 575, 634 (2019).

12. T. Kim, K.-H. Kim, S. Kim, S.-M. Choi, H. Jang, H.-K. Seo, H. Lee, D.-Y. Chung and E. Jang, Nature, 586, 385 (2020).

13. S. Kim, Jin-A Kim, Taehyung Kim, H. Chung, S. Park, S.M. Choi, H.-M. Kim, D.-Y. Chung and E. Jang, Chem. Mater, 32, 12, 5200 (2020).

14. Q. Zhang, X. Gu, Q. Zhang, J. Jiang, X. Jin, F. Li, Z. Chen, F. Zhao, AND Q. Li, Optical Materials Express, 8, 4, 909 (2018).

15. H. Zhang and S. Chen. J. Mater. Chem. C, 7, 2291 (2019).

16. W. Yang, Z. Liu, D.-L. Peng, F. Zhang, H. Huang, Y. Xie, Z. Wu, Applied Surface Science 255, 5669 (2009).

17. J. M. Caruge, J. E. Halpert, V. Wood, V. Bulovic and M. G. Bawebdi, Nature photonics, 2, 247 (2008).

18. S. Oh and J. Kim, Appl. Sci., 9, 4539 (2019)

19. Y.-S. Kim, J.-Y. Choi, Y.-J. Park, S.-H. Choe, Y.-M. Kong, and D. Kim, Korean J. Met. Mater., 57, 324 (2019).

20. D. Kim, T. Lee, and D. Choi, Korean J. Met. Mater., 57, 795 (2019).

21. Y. Kamada, M. Furuta, T Hiramatsu, T. Kawaharamura, D. Wang, S. Shimakawa, C. Li, S. Fujita, T. Hirao, Applied Surface Science, 258695 (2011). 